\title{
Arylamino Substituted Mercaptoimidazole Derivatives as New Corrosion Inhibitors for Carbon Steel in Acidic Media: Experimental and Computational Study
}

\author{
Berrin Duran ${ }^{1 *}$, Leyla Yurttaş ${ }^{2}$, and Murat Duran ${ }^{1}$ \\ ${ }^{1}$ Eskişehir Osmangazi University, Faculty of Science and Letters, Department of Chemistry, 26040, Eskişehir, Turkey \\ ${ }^{2}$ Anadolu University, Faculty of Pharmacy, Department of Pharmaceutical Chemistry, 26470, Eskişehir, Turkey
}

\begin{abstract}
Two arylamino substituted mercaptoimidazole derivatives namely 4,5-dimethyl-1-(phenylamino)-1H-imidazole-2(3H)-thione (I1) and 4,5- dimethyl-1-((p-chlorophenyl)amino)- $1 H$-imidazole-2(3H)-thione (I2) were synthesized and investigated as corrosion inhibitors for carbon steel in $0.5 \mathrm{M} \mathrm{HCl}$ solution by means of electrochemical impedance spectroscopy (EIS), potentiodynamic polarization, ATR-FTIR spectroscopy and SEM. The results showed that the investigated mercaptoimidazole derivatives act as mixed type inhibitors and inhibition efficiency follows the I2>I1 order. Adsorption of inhibitors on metal surface was found to obey the Langmuir adsorption isotherm. Thermodynamic parameters revealed that adsorption of the inhibitors has both physisorption and chemisorption adsorption mechanism. Electrochemical test results were supported by quantum chemical parameters obtained from DFT calculations.
\end{abstract}

Keywords : Carbon Steel, Corrosion, Mercaptoimidazoles

Received : 14 January 2021, Accepted : 8 March 2021

\section{Introduction}

Carbon steel (CS) is one of the most important engineering material used in various industrial applications due to its good mechanical properties and low cost [1-5]. Pickling and descaling with acids are well known industrial processes to remove undesirable scale from steel and ferrous alloy surfaces. $\mathrm{HCl}$ is very often used as industrial acid cleaner during these procedures and leads to metallic corrosion [6-11]. Protection of metals against corrosion is an important task and in order to reduce the economic impact of corrosion, scientists of various fields aim to minimize material loss [12-13]. Among the many methods of corrosion control, use of inhibitors is one of the most practical approaches in these acidic environments and frequently used [14-20]. Inhibitors are organic compounds that prevent corrosion of metals or alloys

*E-mail address: bduran@ogu.edu.tr

DOI: https://doi.org/10.33961/jecst.2021.00045

This is an open-access article distributed under the terms of the Creative Commons Attribution Non-Commercial License (http://creativecommons.org/licenses/by-nc/4.0)
which permits unrestricted non-commercial use, distribution, and reproduction in any which permits unrestricted non-commercial use, distrib
medium, provided the original work is properly cited. by adhering to metal surface or forming a uniform protective film against the corrosive environment when added in small concentrations [21]. Especially, different industrial batch operations and closed-loop systems require addition of inhibitors to the process fluids and solutions in order to reduce the corrosion rate of metals [6].

Recently grate effort has been devoted to finding new and low toxic organic compounds to be used as corrosion inhibitors for carbon steel in acidic solutions [5,6,12,21,22]. Typically, effective inhibitors contain $\mathrm{N}, \mathrm{S}$ or $\mathrm{O}$ atoms in their structures or electronegative functional groups, aromatic rings and $\pi$ electrons in triple or conjugated double bonds which enable to interact with the metal surface via physical or chemical adsorption $[6,23]$. Over the past years, nitrogen containing organic compounds have received considerable attention due to they act as effective corrosion inhibitors and their inhibition mechanism has been explained by lone electron pairs, the p orbital character of free electrons and the electron density around the nitrogen atom [11,24-29]. Currently, corrosion researches are oriented to development of green corrosion inhibitors and use of pharmaceutical com- 

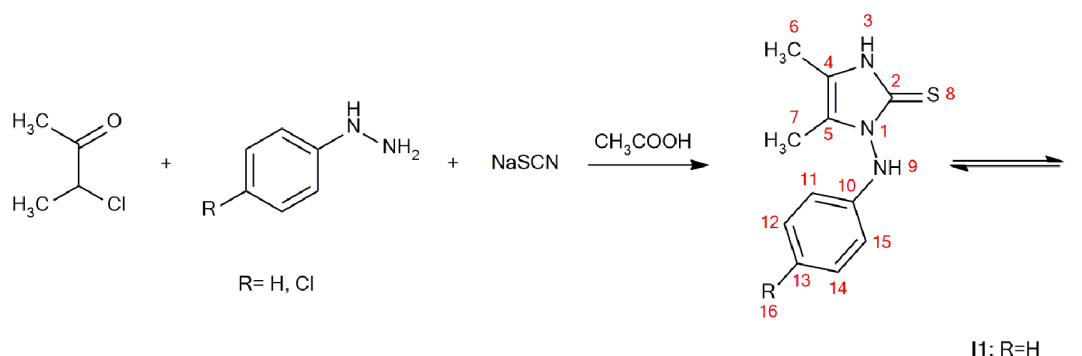<smiles>[R]c1ccc(Nn2c(S)nc(C)c2C)cc1</smiles>

12: $\mathrm{R}=\mathrm{Cl}$

Fig. 1. The synthesis route and general structure of I1 and I2 compounds

pounds to be employed as corrosion inhibitors with good inhibition efficiency and low environmental pollution risk $[5,20]$. Because of their good environmental profiles and high corrosion inhibition performances, imidazoles are one of the potential classes of inhibitors among the various nitrogen containing inhibitor compounds for iron and its alloys in acid media [14,30-34]. As it is known, imidazole and its derivatives are extensively used for synthesis of drug precursor compounds in pharmacology and investigation of drug molecules as corrosion inhibitor has became one of the most actively studied topics in recent years [16,35]. For this reason, imidazole derivatives have been considered as environmentally acceptable compounds and these compounds have many advantages as eco-friendly corrosion inhibitors [5]. Molecules that contain both nitrogen and sulphur (such as mercaptoimidazoles) in their structure are expected to provide acceptable inhibition efficiency than the compounds that contain only nitrogen or sulphur atoms [33,36,37].

The purpose of this study is to evaluate pharmaceutically used mercaptoimidazole derivatives as alternative corrosion inhibitors for low carbon steel in acid media by electrochemical methods, surface analysis techniques and quantum chemical calculations.

\section{Experimental}

\subsection{Synthesis of mercaptoimidazole derivatives}

Synthesis of mercaptoimidazole derivatives was carried out according to the method given in the literature $[35,38]$ and synthesis route was shown in Fig. 1. All chemicals were purchased from Sigma-Aldrich and used as received. The 3-chloro butanone $(10 \mathrm{mmol})$ was dissolved in $50 \mathrm{~mL}$ of acetic acid, and then sodium thiocyanate $(15 \mathrm{mmol})$ was added at room temperature. 1 hour later, phenylhydrazine (or $p$-chlorophenylhydrazine) $(10 \mathrm{mmol})$ were added as drop wise. After the solution becoming dark red, it was mixed for 1-2 hours. When the product started to precipitate in the medium, it was checked with the TLC plates (Merck, silica gel 60 F254) in the solvent mixture of 1:1 ethanol/ethyl acetate. Upon completion of the reaction $50 \mathrm{~mL}$ water was added and washed with water; then the product was filtered and dried. Solid products were crystallized from ethanol in the presence of charcoal, after filtering and drying steps. The yield of pure products was obtained in the range of $58-60 \%$. The resulting mercaptoimidazoles were also shown in Fig. 1. Chemical structure of the synthesized compounds was confirmed by ATRFTIR (Perkin Elmer Spectrum Two), ${ }^{1} \mathrm{H}$ NMR and ${ }^{13}$ C NMR (Jeol ECZ500R, 11.75 Tesla, DMSO- $d_{6}$ containing tetra methyl silane internal standard was used as the solvent) analyses.

\subsection{Spectral data and structure confirmation of synthesized compounds}

4,5-dimethyl-1-(phenylamino)- $1 H$-imidazole2(3H)-thione (I1):

IR $v_{\max }\left(\mathrm{cm}^{-1}\right): 3239(\mathrm{~N}-\mathrm{H}), 3168(\mathrm{~N}-\mathrm{H}), 1359$ $(\mathrm{C}=\mathrm{S}) ;{ }^{1} \mathrm{H}$ NMR $\left(500.16 \mathrm{MHz}, \mathrm{DMSO}-\mathrm{d}_{6}\right)(\delta \mathrm{ppm})$ : $12.00(1 \mathrm{H}, \mathrm{s}, \mathrm{N}-\mathrm{H}), 8.78(1 \mathrm{H}, \mathrm{s}, \mathrm{N}-\mathrm{H}), 7.12(2 \mathrm{H}, \mathrm{t}, J$ $=7.6 \mathrm{~Hz}$, phenyl C3-H, C5-H), $6.73(1 \mathrm{H}, \mathrm{t}, J=7.2$ $\mathrm{Hz}$, phenyl C4-H), 6.43 (2H, d, $J=7.6 \mathrm{~Hz}$, phenyl C2-H, C6-H), 1.97 (3H, s, imidazole C5- $\left.\mathrm{CH}_{3}\right), 1.85$ (3H, s, imidazole $\left.\mathrm{C} 4-\mathrm{CH}_{3}\right) ;{ }^{13} \mathrm{C}$ NMR $(100 \mathrm{MHz}$, DMSO-d $\left.{ }_{6}\right)(\delta \mathrm{ppm}): 8.40\left(\mathrm{CH}_{3}\right), 9.65\left(\mathrm{CH}_{3}\right), 114.55$ (phenyl C2-C6), 117.87 (C4), 122.00 (phenyl C4), 122.67 (C5), 129.54 (phenyl C3-C5), 146.80 (phenyl $\mathrm{C} 1), 160.85(\mathrm{C}=\mathrm{S} \mathrm{C} 2)$. Yield $60 \%$.

4,5- dimethyl-1-((p-chlorophenyl)amino)- $1 H$ imidazole-2(3H)-thione (I2): 
IR $v_{\max }\left(\mathrm{cm}^{-1}\right): 3206(\mathrm{~N}-\mathrm{H}), 3173(\mathrm{~N}-\mathrm{H}), 1358$ $(\mathrm{C}=\mathrm{S}), 799$ (aromatic para); ${ }^{1} \mathrm{H}$ NMR $(500.16 \mathrm{MHz}$, DMSO-d $\left._{6}\right)(\delta \mathrm{ppm}): 12.04(1 \mathrm{H}, \mathrm{s}, \mathrm{N}-\mathrm{H}), 8.99(1 \mathrm{H}, \mathrm{s}$, $\mathrm{N}-\mathrm{H}), 7.16$ (2H, d, $J=8.4 \mathrm{~Hz}$, phenyl C3-H, C5-H), $6.43(2 \mathrm{H}, \mathrm{d}, J=8.4 \mathrm{~Hz}$, phenyl C2-H, C6-H), 1.97 $\left(3 \mathrm{H}, \mathrm{s}\right.$, imidazole $\left.\mathrm{C} 5-\mathrm{CH}_{3}\right), 1.85(3 \mathrm{H}, \mathrm{s}$, imidazole $\left.\mathrm{C} 4-\mathrm{CH}_{3}\right) ;{ }^{13} \mathrm{C}$ NMR $\left(100 \mathrm{MHz}, \mathrm{DMSO}-\mathrm{d}_{6}\right)(\delta \mathrm{ppm})$ : $8.32\left(\mathrm{CH}_{3}\right), 9.61\left(\mathrm{CH}_{3}\right), 114.42$ (phenyl C2-C6), 117.91 (C4), 122.57 (C5), 123.58 (phenyl C4), 129.29 (phenyl C3-C5), 146.77 (phenyl C1), 160.94 $(\mathrm{C}=\mathrm{S} \mathrm{C} 2)$. Yield 58\%.

\subsection{Electrodes}

Corrosion tests were performed on 1020 type low carbon steel with the following chemical composition (wt. \%) C 0.15\%, Mn 0.30\%, P 0.04\%, Si 0.10\%, S $0.05 \%$ and the rest Fe. Working electrode (WE) was prepared by embedding a cylindrical rod of carbon steel into a Teflon holder using polyester. Before tests, the exposed WE surface $\left(0.283 \mathrm{~cm}^{2}\right)$ was mechanically polished by Forcipol $1 \mathrm{~V}$ grinder/polisher with a series of emery papers $(800,1000$ and 1200 grits) and cleaned ultrasonically in $1: 1(\mathrm{v} / \mathrm{v})$ ethanol/acetone mixture, then rinsed by water. A platinum wire $(99.9 \%$, Aldrich) was used as counter electrode (CE) and the $\mathrm{Ag} / \mathrm{AgCl}$ electrode $(3 \mathrm{M} \mathrm{KCl}$, Gamry) was used as the reference electrode (RE).

\subsection{Solutions}

All the solutions of inhibitors were containing 3\% (v/v) dimethyl sulfoxide (DMSO) as co-solvent to ensure solubility, due to synthesized mercaptoimidazoles are insoluble in water. Test solutions $(100 \mathrm{~mL})$ were prepared by dissolving accurately weighed quantity of each inhibitor in $3 \mathrm{~mL}$ DMSO, diluting with ultra pure water (Puris, $18.6 \mathrm{M} \Omega$ ) and then adding required amount of concentrated $\mathrm{HCl}(37 \%$, Sigma) for $0.5 \mathrm{M}$ acid concentration. In order to eliminate the effect of DMSO, $0.5 \mathrm{M} \mathrm{HCl}$ solution containing 3\% DMSO was used as the blank solution and corrosion rate of carbon steel was determined in this solution, at first. The concentration range of the inhibitor solutions employed was $1 \times 10^{-5} \mathrm{M}$ to $1 \times 10^{-3}$ $\mathrm{M}$ in presence of $0.5 \mathrm{M} \mathrm{HCl}$.

\subsection{Electrochemical measurements}

All electrochemical experiments were performed in a one compartment corrosion cell with three electrodes connected to Gamry Reference 600 potentio-
stat/galvanostat/ZRA system, which was interfaced to a personal computer to control the experiments by Gamry Framework software. Experiments were carried out with freshly prepared, unstirred $0.5 \mathrm{M} \mathrm{HCl}$ solutions without or with different concentrations of inhibitors as open to atmosphere at $25^{\circ} \mathrm{C}$. EIS measurements were performed at open circuit potential $\left(\mathrm{E}_{\text {ocp }}\right)$ with $10 \mathrm{mV}$ AC voltage amplitude in the frequency range from $100 \mathrm{kHz}$ to $10 \mathrm{mHz}$ after $30 \mathrm{~min}$ utes of immersion in test solution to attain a stable $\mathrm{E}_{\text {ocp }}$ value. Subsequently, potentiodynamic polarization curves were recorded in the potential range of $0.3 \mathrm{~V}$ to $+0.3 \mathrm{~V}$ versus $\mathrm{E}_{\mathrm{ocp}}$ with the scan rate of $1 \mathrm{mV} \mathrm{s}^{-1}$. The analysis of EIS data was done by fitting impedance spectra to equivalent circuits using ZSimpWin (version 3.21) software, which allowed the chi-square value $\left(\chi^{2}\right.$, i.e. the sum of the square of the differences between theoretical and experimental points) to judge quality of equivalent circuit fitting. Gamry Echem Analyst software was used for Tafel extrapolation of the potentiodynamic polarization curves and corrosion kinetic parameters including anodic and cathodic Tafel slopes $\left(\beta_{\mathrm{a}}\right.$ and $\left.\beta_{\mathrm{c}}\right)$, corrosion potential $\left(\mathrm{E}_{\text {corr }}\right)$, corrosion current density $\left(\mathrm{i}_{\text {corr }}\right)$ and corrosion rate $(\mathrm{CR})$ values were obtained. All the experiments were repeated three times for each condition and average values were presented.

\subsection{Surface characterization}

Perkin Elmer Spectrum Two ATR-FTIR spectrophotometer was used to record ATR-FTIR spectra of the steel samples at the end of $1 \mathrm{~h}$ immersion (duration of electrochemical measurements) in $0.5 \mathrm{M} \mathrm{HCl}$ without and with $1 \times 10^{-3} \mathrm{M}$ inhibitor and surface morphologies of the these samples were investigated by Hitachi Regulus 8230 model field emission scanning electron microscope (FE-SEM) under $1.5 \mathrm{kX}$ constant magnification to provide a constant view.

\subsection{Quantum chemical calculations}

Quantum chemical calculations of the investigated compounds were carried out at liquid phase using density functional theory (DFT) method with the hybrid function of Becke's three parameters exchange function and Lee, Yang and Parr nonlocal correlation function (B3LYP) at the 6-311G $(\mathrm{d}, \mathrm{p})$ basis set implemented in Gaussian 03W programme package employing personal computer with processor Core i7 (6 Core $\mathrm{CPU}, 3.20 \mathrm{GHz}$ ) [5]. Molecular parameters such as 
$\mathrm{E}_{\text {номо }}$ (energy of the highest occupied molecular orbital), $\mathrm{E}_{\mathrm{LUMO}}$ (energy of the lowest unoccupied molecular orbital), energy gap $\left(\Delta \mathrm{E}=\mathrm{E}_{\mathrm{LUMO}}-\mathrm{E}_{\mathrm{HOMO}}\right)$, (dipole moment) and Mulliken charges of the investigated mercaptoimidazole compounds were calculated.

\section{Results and Discussion}

\subsection{Electrochemical impedance spectroscopy}

Corrosion inhibition performances of the synthesized mercaptoimidazoles were investigated by electrochemical impedance spectroscopy and impedance spectra of steel in presence of I1 and I2 compounds were recorded. Fig. 2 shows the Nyquist plots of carbon steel in $0.5 \mathrm{M} \mathrm{HCl}$ solution with and without different concentrations of inhibitors at $25^{\circ} \mathrm{C}$. All the impedance curves consist of one single capacitive loop represented by imperfect semi-circle for both compounds. This capacitive loop indicates charge transfer controlled corrosion process of steel in $0.5 \mathrm{M}$ $\mathrm{HCl}$ solution and formation of a protective layer on the metal surface. Deviations from the ideal semi-circle are attributed to the frequency dispersion resulted from the roughness or inhomogeneities of electrode surface and mass transport process [5,39-42]. The diameter of the semicircle increases when the concentration of inhibitor rises; this increase refers to adsorption of inhibitor molecules on the metal surface and higher surface coverage of steel [43,44]. Similar shapes of impedance curves recorded in all cases reveal that addition of mercaptoimidazoles does not affect the dissolution mechanism of carbon steel in $\mathrm{HCl}$ media [42,45-48].

All experimental spectra were fitted with the $\mathrm{R}(\mathrm{QR})$ equivalent circuit shown in Fig. 3, to find the parameters describing and being consistent with the experimental data and behaviour of the metal/solution interface was tried to be clarified in the absence and presence of mercaptoimidazoles. The elements of the circuit can be named as $R_{S}$ (solution resistance), $\mathrm{R}_{\mathrm{ct}}$ (charge transfer resistance) and $\mathrm{Q}$ (constant phase element, CPE) reflecting a non-ideal capacitor due to imperfect nature of impedance curves and the impedance of CPE is represented by the below expression $[7,49]$ :

$$
Z_{C P E}=\left[Y_{o}(j \omega)^{n}\right]^{-1}
$$

where $Y_{o}$ is the magnitude of CPE, $j$ is the imaginary
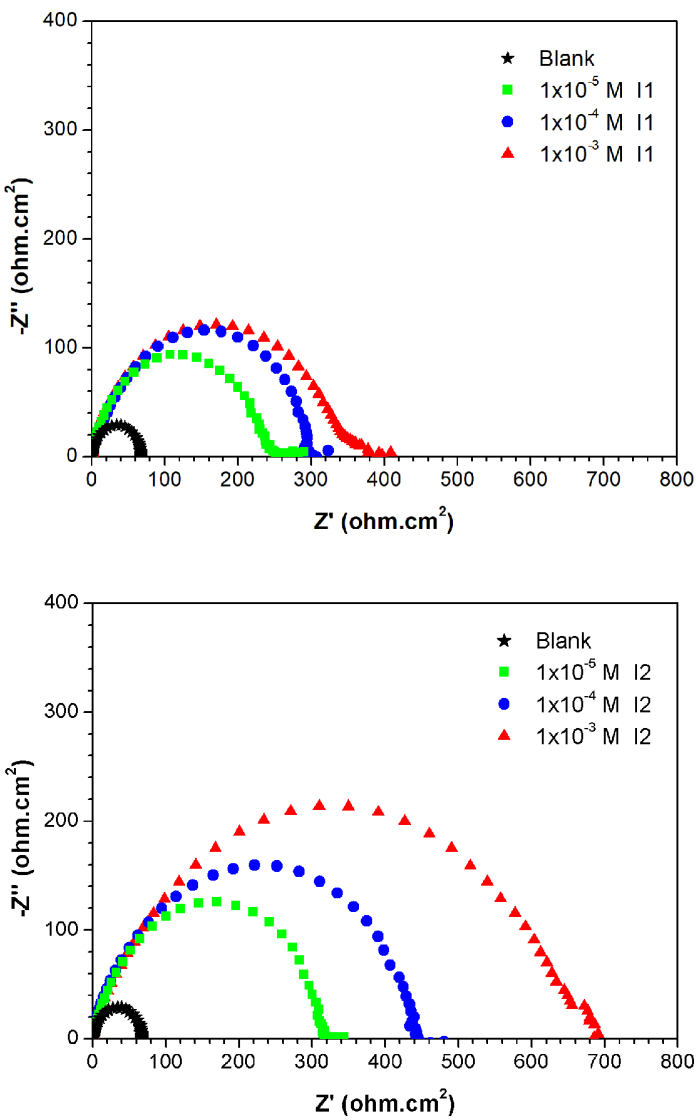

Fig. 2. Nyquist plots of 1020 steel in $0.5 \mathrm{M} \mathrm{HCl}$ solution without and with different concentrations of I1 and I2.

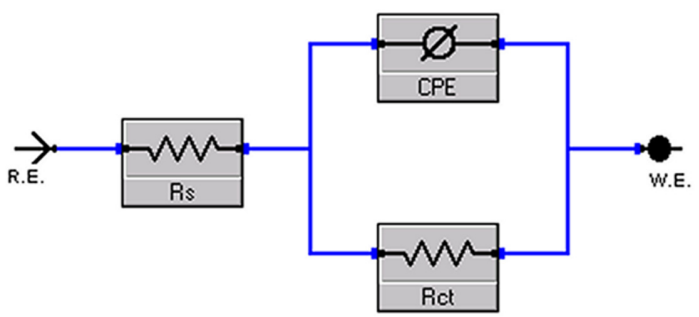

Fig. 3. Electrical equivalent circuit used for modelling metal/solution interface in the absence and presence of inhibitors.

unit, $\omega$ is the angular frequency and $n$ is the phase shift which is gives information about the degree of surface roughness and CPE is equal to an ideal capacitor when $\mathrm{n}=1$.

The parameters obtained from fitting results and 
Table 1. Impedance parameters for 1020 steel in $0.5 \mathrm{M} \mathrm{HCl}$ in the absence and presence of different concentrations of I1 and $\mathrm{I} 2$ at $298 \mathrm{~K}$

\begin{tabular}{ccccccccc}
\hline \hline Inhibitor & $\begin{array}{c}\mathrm{C} \\
(\mathrm{mol} / \mathrm{L})\end{array}$ & $\begin{array}{c}\mathrm{R}_{\mathrm{s}} \\
\left(\mathrm{ohm} . \mathrm{cm}^{2}\right)\end{array}$ & $\begin{array}{c}\mathrm{Y}_{\mathrm{o}} \\
\left(\mathrm{Ss}^{-\mathrm{n}} / \mathrm{cm}^{2}\right)\end{array}$ & $\mathrm{n}$ & $\begin{array}{c}\mathrm{R}_{\mathrm{ct}} \\
\left(\mathrm{ohm} . \mathrm{cm}^{2}\right)\end{array}$ & $\chi^{2}$ & $\begin{array}{c}\eta_{\text {EIS }} \\
(\%)\end{array}$ & $\theta$ \\
\hline- & - & 0.49 & $3.14 \times 10^{-4}$ & 0.89 & 67.1 & $1.24 \times 10^{-3}$ & - & - \\
\hline $\mathrm{I} 1$ & $1 \times 10^{-5}$ & 0.50 & $1.91 \times 10^{-4}$ & 0.83 & 251.9 & $1.33 \times 10^{-3}$ & 73.36 & 0.7336 \\
& $5 \times 10^{-5}$ & 0.37 & $1.25 \times 10^{-4}$ & 0.85 & 285.4 & $1.47 \times 10^{-3}$ & 76.49 & 0.7649 \\
& $1 \times 10^{-4}$ & 0.38 & $1.12 \times 10^{-4}$ & 0.84 & 299.5 & $3.78 \times 10^{-3}$ & 77.60 & 0.7760 \\
& $5 \times 10^{-4}$ & 0.27 & $9.62 \times 10^{-5}$ & 0.86 & 322.0 & $4.38 \times 10^{-3}$ & 79.16 & 0.7916 \\
& $1 \times 10^{-3}$ & 0.58 & $7.71 \times 10^{-5}$ & 0.86 & 348.0 & $5.94 \times 10^{-3}$ & 80.72 & 0.8072 \\
\hline $\mathrm{I} 2$ & $1 \times 10^{-5}$ & 0.65 & $1.67 \times 10^{-4}$ & 0.83 & 324.2 & $3.88 \times 10^{-4}$ & 79.30 & 0.7930 \\
& $5 \times 10^{-5}$ & 0.31 & $7.94 \times 10^{-5}$ & 0.86 & 363.0 & $3.69 \times 10^{-3}$ & 81.52 & 0.8152 \\
& $1 \times 10^{-4}$ & 0.18 & $6.17 \times 10^{-5}$ & 0.87 & 433.9 & $8.54 \times 10^{-3}$ & 84.54 & 0.8454 \\
& $5 \times 10^{-4}$ & 0.19 & $7.04 \times 10^{-5}$ & 0.82 & 578.6 & $1.03 \times 10^{-2}$ & 88.40 & 0.8840 \\
& $1 \times 10^{-3}$ & 0.19 & $6.23 \times 10^{-5}$ & 0.82 & 636.9 & $1.55 \times 10^{-3}$ & 89.46 & 0.8946 \\
\hline
\end{tabular}

calculated values of inhibition efficiencies $(\eta)$ and surface coverage degrees $(\theta)$ for each inhibitor were listed in Table 1. Inhibition efficiencies were calculated using the following equation, where $R_{\mathrm{ct}}$ and $R_{c t}^{o}$ are the charge transfer resistance of steel with and without inhibitors, respectively [50].

$$
\eta_{E I S}(\%)=\frac{R_{c t}-R_{c t}^{o}}{R_{c t}} \times 100
$$

The data of Table 1 show that, the $\mathrm{R}_{\mathrm{s}}$ values are very small compared to the $R_{c t}$ values. The increase of $R_{c t}$ values with increasing inhibitor concentration suggests the formation of protective layer on the metal/electrode interface. It can be seen that, while $R_{c t}$ values increase $Q$ values decrease as a general trend with increasing inhibitor concentration and this case can be related to a decrease in the electrical capacity of non-ideal capacitor formed between metal and solution due to formation of protective layer. This layer acts as a barrier for mass and charge transfer [51,52]. According to EIS data, inhibition efficiency follows the I2>I1 order.

\subsection{Potentiodynamic polarization}

The effect of various concentrations of I1 and I2 compounds on the polarization behaviour of low carbon steel in $0.5 \mathrm{M} \mathrm{HCl}$ solution was shown in Fig. 4. Compared with the blank experiment, anodic and cathodic parts of the polarization curves were shifted to the lower current density region in presence of
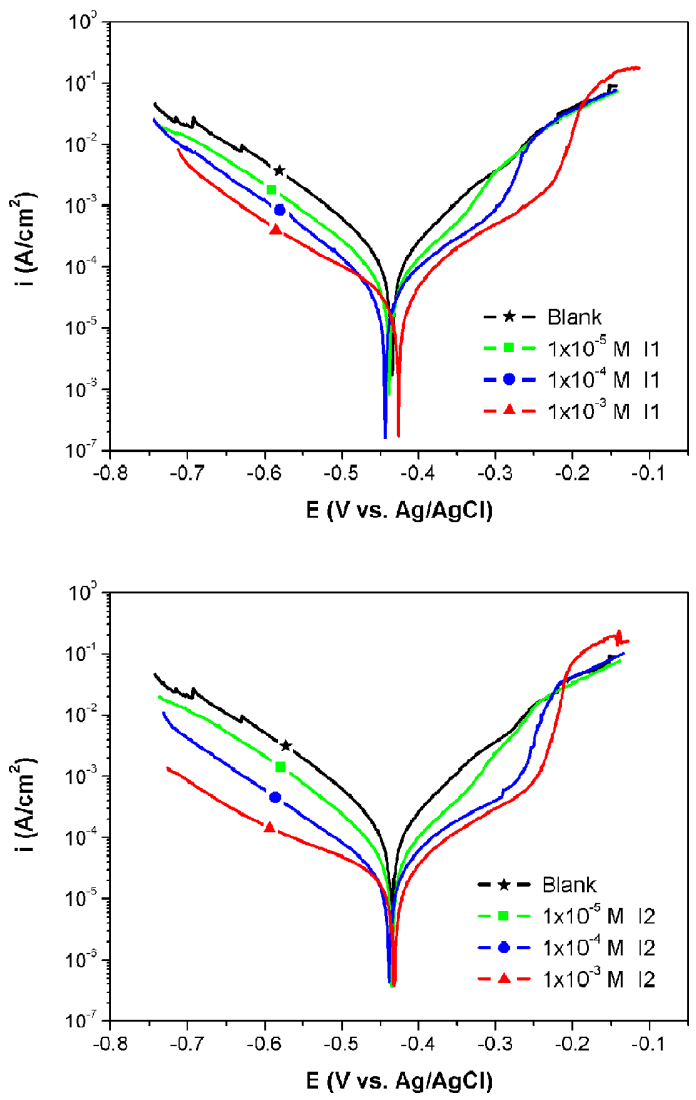

Fig. 4. Potentiodynamic polarization curves of 1020 steel in $0.5 \mathrm{M} \mathrm{HCl}$ without and with different concentrations of I1 and I2. 
Table 2. Potentiodynamic polarization parameters for 1020 steel in $0.5 \mathrm{M} \mathrm{HCl}$ in the absence and presence of different concentrations of I1 and I2 at $298 \mathrm{~K}$

\begin{tabular}{ccccccccc}
\hline \hline Inhibitor & $\begin{array}{c}\mathrm{C} \\
(\mathrm{mol} / \mathrm{L})\end{array}$ & $\begin{array}{c}\mathrm{i}_{\text {corr }} \\
\left(\mu \mathrm{A} / \mathrm{cm}^{2}\right)\end{array}$ & $\begin{array}{c}\mathrm{E}_{\text {corr }} \\
(\mathrm{mV})\end{array}$ & $\begin{array}{c}\beta_{\mathrm{a}} \\
(\mathrm{mV})\end{array}$ & $\begin{array}{c}\beta_{\mathrm{c}} \\
(\mathrm{mV})\end{array}$ & $\begin{array}{c}\mathrm{C}_{\mathrm{R}} \\
(\mathrm{mpy})\end{array}$ & $\begin{array}{c}\eta_{\mathrm{P}} \\
(\%)\end{array}$ & $\theta$ \\
\hline- & - & 133.0 & -435 & 94.20 & 91.80 & 61.08 & - & - \\
\hline \multirow{2}{*}{$\mathrm{I} 1$} & $1 \times 10^{-5}$ & 77.30 & -438 & 108.1 & 105.1 & 35.36 & 41.88 & 0.4188 \\
& $5 \times 10^{-5}$ & 62.60 & -438 & 113.6 & 113.3 & 28.66 & 52.93 & 0.5293 \\
& $1 \times 10^{-4}$ & 50.80 & -444 & 116.9 & 113.8 & 23.27 & 61.80 & 0.6180 \\
& $5 \times 10^{-4}$ & 44.60 & -437 & 95.60 & 135.6 & 20.40 & 66.47 & 0.6647 \\
& $1 \times 10^{-3}$ & 40.90 & -427 & 103.3 & 164.9 & 18.72 & 69.25 & 0.6925 \\
\hline I2 & $1 \times 10^{-5}$ & 61.30 & -435 & 107.0 & 104.2 & 28.03 & 53.91 & 0.5391 \\
& $5 \times 10^{-5}$ & 42.80 & -437 & 101.5 & 135.3 & 19.59 & 67.82 & 0.6782 \\
& $1 \times 10^{-4}$ & 39.50 & -439 & 116.4 & 164.3 & 18.09 & 70.30 & 0.7030 \\
& $5 \times 10^{-4}$ & 32.40 & -439 & 129.7 & 159.9 & 14.84 & 75.64 & 0.7564 \\
& $1 \times 10^{-3}$ & 23.80 & -430 & 83.00 & 211.2 & 10.87 & 82.11 & 0.8211 \\
\hline
\end{tabular}

inhibitors; also corrosion current density decreased with increasing inhibitor concentration. This implies that addition of the mercaptoimidazoles reduces corrosion rate of steel by suppressing anodic dissolution and cathodic hydrogen evolution reactions. Furthermore, it was observed that addition of I1 and I 2 compounds does not cause to noticeable shift in corrosion potential with respect to the $\mathrm{E}_{\text {corr }}$ of blank experiment. Comparison of $\mathrm{E}_{\mathrm{corr}}$ values confirms that both of the I1 and 2 compounds behave as mixed type inhibitor due to shifts in corrosion potentials less than $85 \mathrm{mV}$ $[48,53]$. Tafel extrapolation method was applied to obtain corrosion parameters such as corrosion current density $\left(\mathrm{i}_{\text {corr }}\right)$, corrosion potential $\left(\mathrm{E}_{\mathrm{corr}}\right)$, anodic and cathodic Tafel slopes $\left(\beta_{\mathrm{a}}\right.$ and $\left.\beta_{\mathrm{c}}\right)$, inhibition efficiency $\left(\eta_{P}\right)$, corrosion rate $\left(C_{R}\right)$, surface coverage degree $(\theta)$ and these parameters were listed in Table 2 . The inhibition efficiencies were calculated from the following equation [50], where $i$ and $i_{o}$ are the corrosion current densities with and without inhibitor, respectively.

$$
\eta_{P}(\%)=\frac{i_{o}-i}{i_{o}} \times 100
$$

Table 2 shows that the value of $i_{\text {corr }}\left(\right.$ and $C_{R}$ ) in presence of mercaptoimidazoles is considerably lower as compared to obtained in the absence of mercaptoimidazoles and this suggests that investigated compounds are effective corrosion inhibitors. Additionally, change of anodic and cathodic Tafel slopes reveals that the investigated compounds control both of the anodic and cathodic reactions; but the values of $\beta_{c}$ are comparatively more affected than the values of $\beta_{\mathrm{a}}$ in presence of inhibitors with respect to the same values of blank, which suggesting that the cathodic reaction is more effective in corrosion inhibition process of carbon steel by these compounds [49]. Potentiodynamic polarization results indicate that inhibition efficiency of mercaptoimidazoles follows the I2>I1 order.

\subsection{Adsorption isotherm and thermodynamic parameters}

Interaction of inhibitors with metal surface can be characterized by adsorption isotherms. Two main types of interaction including physisorption and chemisorption can be used to describe adsorption behaviour of the inhibitors [54-56]. These processes depend on the chemical structures of the inhibitor molecules. The linear relation between surface coverage degree and inhibitor concentration is explored to get adsorption isotherm. In order to analyse the adsorption process of investigated mercaptoimidazoles, various adsorption isotherms (Langmuir, Freundlich, Temkin and Frumkin) were tested graphically according to data acquired from the polarization curves and higher linear correlation coefficients $\left(\mathrm{R}^{2}\right)$ were obtained for Langmuir adsorption isotherm, which indicates that adsorption of I1 and I 2 inhibitors 
on the 1020 steel obeys the Langmuir adsorption model. According to this model, $\theta$ is related to $\mathrm{C}$ by the following equation [44]:

$$
\frac{C}{\theta}=\frac{1}{K_{a d s}}+C
$$

where $\mathrm{C}$ is the inhibitor concentration, $\theta$ is the surface coverage degree $(\theta=\mathrm{IE} / 100), \mathrm{K}_{\mathrm{ads}}$ is the adsorption equilibrium constant. Based on the above equation plot of $\mathrm{C} / \theta$ versus $\mathrm{C}$ yields the straight line with high $\mathrm{R}^{2}$ value for I1 and I2 inhibitors as shown in Fig. 5. This suggests that uniform and monolayer Langmuir type adsorption of studied inhibitor molecules occurs on the steel surface in $0.5 \mathrm{M} \mathrm{HCl}$ solution and all adsorption sites are equivalent with no interaction with the neighbour sites being occupied $[57,58] . K_{\text {ads }}$ parameters were calculated from the intercept of straight lines seen at Fig. 5. $K_{\text {ads }}$ is related to the standard Gibbs free energy of adsorption $\left(\Delta G_{\text {ads }}^{o}\right)$ and expressed by following equation, where 55.5 is the molar concentration of water in the solution, $R$ is the gas constant $\left(8.314 \mathrm{~J} \mathrm{~K}^{-1} \mathrm{~mol}^{-1}\right)$ and $T$ is the absolute temperature $(\mathrm{K})$.

$$
K_{a d s}=\frac{1}{55.5} \exp \left(\frac{-\Delta G_{a d s}^{o}}{R T}\right)
$$

Thermodynamic parameters acquired from the Langmuir adsorption isotherms of the compounds were given in Table 3. Calculated $\mathrm{K}_{\mathrm{ads}}$ values are $5.08 \times 10^{4}$ and $5.24 \times 10^{4}$ for I 1 and I 2 compounds. In literature, it was reported that the high $\mathrm{K}_{\text {ads }}$ values (> $\sim 100 \mathrm{M}^{-1}$ ) attributed to the stronger and more stable adsorbed layer formation on the metal surface $[50,59]$. Relatively high values of $K_{a d s}$ reflect the strong interaction between the steel surface and mercaptoimidazole compounds. According to literature, value of standard Gibbs free energy $\left(\Delta G_{\text {ads }}^{o}\right.$ ) of adsorption when equal to $-20 \mathrm{~kJ} \mathrm{~mol}^{-1}$ or lower indicates electrostatic interaction between the molecules and the metal (physisorption), whereas $-40 \mathrm{~kJ} \mathrm{~mol}^{-1}$ or higher shows chemisorption (charge sharing between inhibitor molecules and metal) [46,47]. The calculated $\Delta G_{\text {ads }}^{o}$ values are -36.80 and $-36.87 \mathrm{~kJ}$ $\mathrm{mol}^{-1}$ for I1 and I2 compounds; these values reveal that the adsorption of studied mercaptoimidazole compounds on low carbon steel is physisorption. On the other hand it is stated in literature that, since the calculated $\Delta G_{\text {ads }}^{o}$ values are very close to $-40 \mathrm{~kJ} / \mathrm{mol}$ threshold value, adsorption of compounds may occur
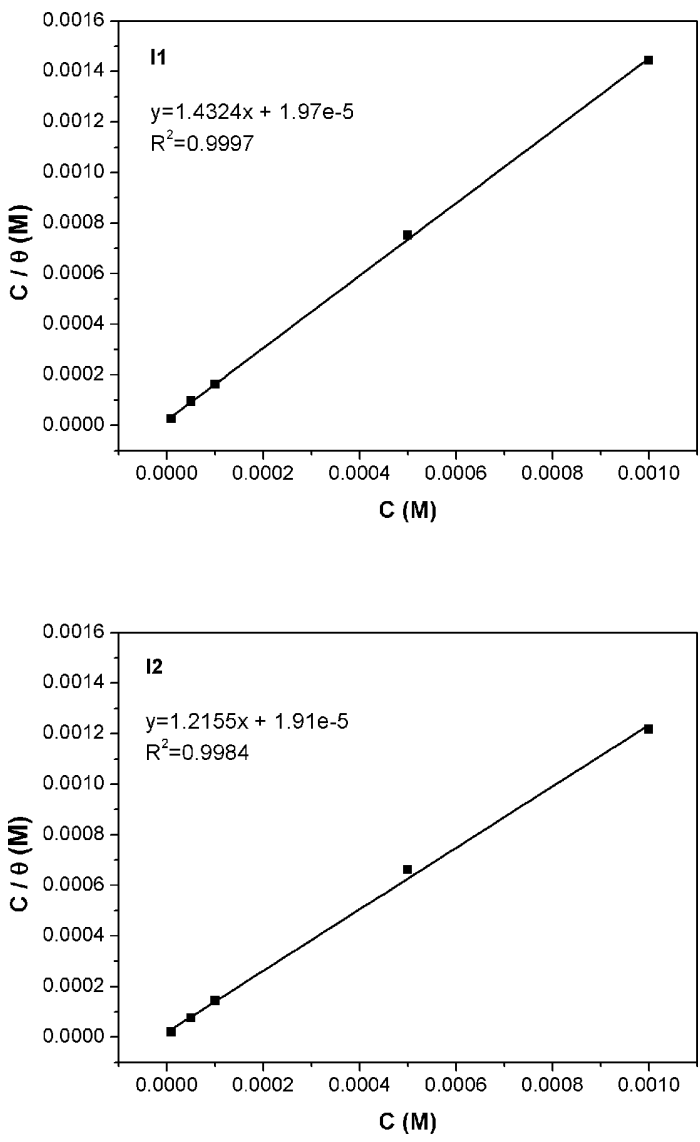

Fig. 5. Langmuir adsorption isotherms obtained from potentiodynamic polarization data of 1020 steel in presence of I1 and I 2 compounds at $298 \mathrm{~K}$.

Table 3. Thermodynamic parameters calculated from Langmuir adsorption isotherm at $298 \mathrm{~K}$ for the studied mercaptoimidazoles

\begin{tabular}{ccc}
\hline \hline Inhibitor & $\mathrm{K}_{\text {ads }}\left(\mathrm{M}^{-1}\right)$ & $\Delta \mathrm{G}_{\text {ads }}(\mathrm{kJ} / \mathrm{mol})$ \\
\hline $\mathrm{I} 1$ & $5.08 \times 10^{4}$ & -36.80 \\
$\mathrm{I} 2$ & $5.24 \times 10^{4}$ & -36.87 \\
\hline
\end{tabular}

by chemisorption as well as physisorption $[58,60$ 62]. Calculated adsorption free energy values suggest that adsorption type of studied compounds is mainly physical adsorption besides slight chemical adsorption.

\subsection{FTIR spectra}

The reflectance FTIR spectra of the inhibited 1020 steel samples were depicted in Fig. 6. In these spec- 


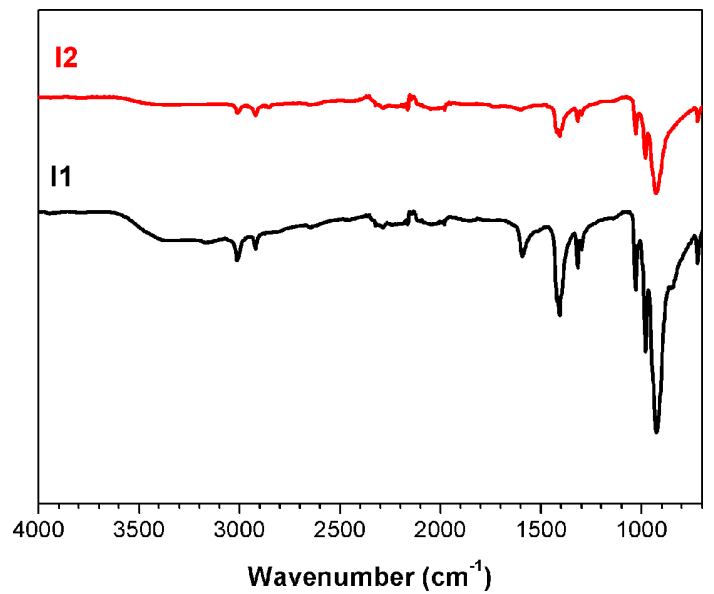

Fig. 6. ATR-FTIR spectra of the 1020 steel samples after $24 \mathrm{~h}$ immersion period in $0.5 \mathrm{M} \mathrm{HCl}$ solutions in the absence and presence of $1 \times 10^{-3} \mathrm{M}$ inhibitor.

tra, weak bands observed at 3013 and $2920 \mathrm{~cm}^{-1}$ belong to asymmetric and symmetric stretching vibrations of aromatic C-H's. Weak signals located at around $2650 \mathrm{~cm}^{-1}$ arise from S-H stretching vibrations. Weak signals in the region of $1595-1610 \mathrm{~cm}^{-1}$ reflect $\mathrm{C}=\mathrm{N}$ stretching, medium peaks at 1408 and $1318 \mathrm{~cm}^{-1}$ indicate $\mathrm{C}-\mathrm{N}$ stretching vibrations. The peaks at 926 and $980 \mathrm{~cm}^{-1}$ are assigned to $\mathrm{C}=\mathrm{S}$, while the strong bands at $922 \mathrm{~cm}^{-1}$ and $980 \mathrm{~cm}^{-1}$ attributed to the stretching vibrations of $-\mathrm{CH}_{3}$ groups. Signals in the range of 719-722 $\mathrm{cm}^{-1}$ are correspond to $\mathrm{N}-\mathrm{H}$ bending vibrations. Observation of main peaks in these spectra for both compounds confirms that the steel surface is covered with mercaptoimidazole inhibitors.

\subsection{Surface morphology}

Surfaces of low carbon steel samples were investigated by SEM in both uninhibited and inhibited solutions to confirm the effectiveness of the inhibitors. Fig. 7 shows the morphologies of the steel samples at the end of $1 \mathrm{~h}$ immersion time in $0.5 \mathrm{M} \mathrm{HCl}$ without and with $1 \times 10^{-3} \mathrm{M} \mathrm{I} 1$ and I2 inhibitors. It is clearly seen that the steel surface was seriously and uniformly damaged in the absence of inhibitor due to the metal dissolution in aggressive solution and large number of small pits were distributed all over the surface. SEM micrographs recorded in presence of mercaptoimidazoles show that, the addition of these

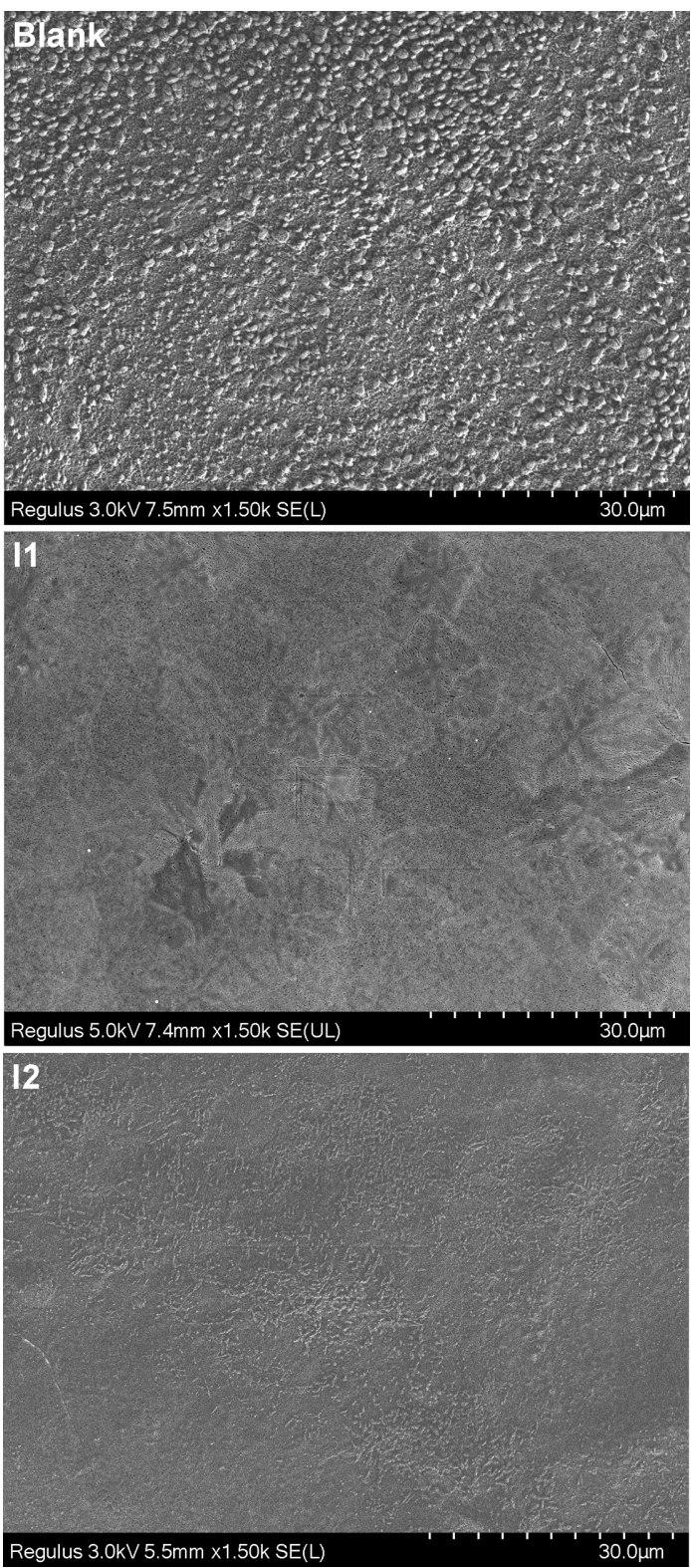

Fig. 7. SEM micrographs of the 1020 steel surfaces after 1 $\mathrm{h}$ immersion in $0.5 \mathrm{M} \mathrm{HCl}$ solutions in the absence and presence of $1 \times 10^{-3} \mathrm{M}$ inhibitor.

compounds modifies the features of the steel surface; and damaged, graven steel surface replaced to much smooth surfaces. Especially in presence of I2, steel surface has better conditions and it seems more homogeneous compared to the I1. As indicated by SEM images, both of the compounds act as corrosion 


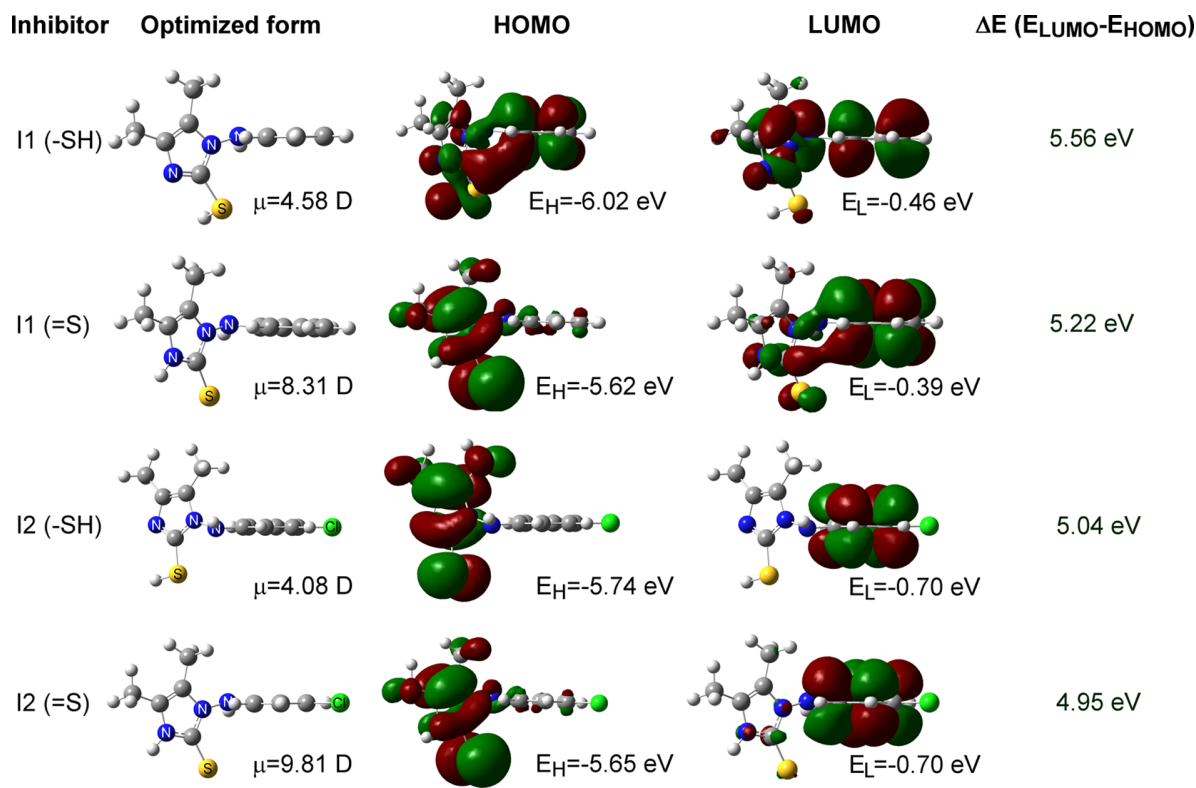

Fig. 8. HOMO and LUMO populations and calculated quantum chemical parameters for both of the thiol (-SH) and thione $(=\mathrm{S})$ forms of I1 and I2 inhibitors.

inhibitor and suppress the dissolution of steel by forming protective adsorption layer on steel surface thereby reduce the corrosion rate of metal. Furthermore, I 2 is more effective inhibitor than I1 under the same conditions for low carbon steel in $0.5 \mathrm{M} \mathrm{HCl}$, which is in good agreement with the electrochemical test results.

\subsection{Quantum chemical studies}

Certain quantum chemical parameters such as energy of the lowest unoccupied molecular orbital $\left(\mathrm{E}_{\mathrm{LUMO}}\right)$, energy of the highest occupied molecular orbital $\left(\mathrm{E}_{\mathrm{HOMO}}\right)$, band gap $\left(\Delta \mathrm{E}_{\mathrm{LUMO}}\right.$-номо $)$, dipole moment $(\mu)$ and Mulliken charges are utilized for explanation of corrosion inhibition mode of inhibitors. In this respect, many of corrosion studies include quantum chemical calculations in order to support experimental data $[5,7,18,20,23,48,50,53,60]$.

Quantum chemical calculations were performed at density function theory (DFT) level in liquid phase using 6-311G(d,p) basis set to explore the relationships between electronic structures and inhibition performances of the investigated mercaptoimidazoles. Optimized geometric structures and distribution of electrons in HOMO and LUMO frontier molecular orbitals are presented in Fig. 8, for both thiol and thione tautomeric forms of the inhibitors (I1 and $\mathrm{I} 2$ compounds can be either in these tautomeric forms depending to solution conditions). The calculated quantum chemical parameters $\left(\mathrm{E}_{\mathrm{HOMO}}, \mathrm{E}_{\mathrm{Lumo}}\right.$, $\Delta \mathrm{E}$ and $\mu$ ) are given in Fig. 8 (The isovalue was selected as 0.02 for visualization).

As it can be seen from the optimized structures in Fig. 8, investigated mercaptoimidazoles are not planar, due to imidazole and benzene rings are in different planes. Therefore, the entire molecule cannot hold on to the metal surface at the same time, which may result in relatively weak interaction between molecules and metal surface during adsorption. The atoms and groups of the molecules may interact with the electrode surface depending on the geometry of the inhibitor as well as the nature of their frontier molecular orbitals. Frontier molecular orbital theory is very useful in predicting the adsorption centres. As shown in Fig. 8, HOMO of I2 concentrated mostly on imidazole ring, while LUMO is located over the benzene ring for both of the thiol and thione forms of I2. On the other hand, thione form of I1 is similar to HOMO and LUMO distributions of I2, while HOMO and LUMO locations are more general and distributed over the molecule for thiol form of I1. This phenomenon can be attributed to the presence of $\mathrm{Cl}$ atom 
Table 4. Calculated atomic charges of I1 and I2 compounds

\begin{tabular}{ccccc}
\hline \hline $\begin{array}{c}\text { Charge of atoms } \\
\text { (Mulliken) }\end{array}$ & I1 (-SH) & I1 (=S) & I2 (-SH) & I2 (=S) \\
\hline 1N & -0.283 & -0.305 & -0.307 & -0.307 \\
2C & 0.106 & 0.219 & 0.177 & 0.219 \\
3N & -0.354 & -0.373 & -0.387 & -0.372 \\
$4 \mathrm{C}$ & -0.086 & 0.040 & -0.091 & 0.041 \\
$5 \mathrm{C}$ & 0.119 & 0.075 & 0.109 & 0.075 \\
$6 \mathrm{C}$ & -0.246 & -0.236 & -0.245 & -0.236 \\
$7 \mathrm{C}$ & -0.232 & -0.226 & -0.244 & -0.226 \\
$8 \mathrm{~S}$ & -0.055 & -0.483 & -0.038 & -0.476 \\
$9 \mathrm{~N}$ & -0.326 & -0.318 & -0.335 & -0.317 \\
$10 \mathrm{C}$ & 0.139 & 0.146 & 0.139 & 0.150 \\
$11 \mathrm{C}$ & -0.099 & -0.095 & -0.122 & -0.086 \\
$12 \mathrm{C}$ & -0.133 & -0.134 & -0.001 & -0.006 \\
$13 \mathrm{C}$ & -0.132 & -0.132 & -0.261 & -0.261 \\
$14 \mathrm{C}$ & -0.128 & -0.129 & -0.003 & -0.003 \\
$15 \mathrm{C}$ & -0.131 & -0.132 & -0.088 & -0.122 \\
$16 \mathrm{Cl}$ & - & - & -0.111 & -0.111 \\
\hline & & & & \\
\hline
\end{tabular}

in the $\mathrm{I} 2$ compound. The electronegative $\mathrm{Cl}$ atom connected to the benzene ring withdraws electron inductively from the benzene ring and mesomerically donates electrons to the benzene ring. The electrons donated to the ring are withdrawn by the $\mathrm{N}$ atoms of imidazole ring and lead to an increase in the electron density of the imidazole ring. Therefore, the probability of stronger adhesion to the steel surface via imidazole ring increase and the inhibitor I 2 shows better inhibition performance. According to frontier molecule orbital theory, $\mathrm{E}_{\mathrm{HOMO}}$ is the measure of electron donating ability and $\mathrm{E}_{\mathrm{LUMO}}$ is the measure of electron accepting ability of the molecule. In this respect, the high value of $\mathrm{E}_{\text {HOMO }}$ for an inhibitor is associated with the high tendency of offering electrons to vacant orbital of the metal and better inhibition efficiency. In addition, energy gap $\Delta \mathrm{E}\left(\mathrm{E}_{\mathrm{LuMO}^{-}}\right.$ $\left.\mathrm{E}_{\mathrm{HOMO}}\right)$ is another important parameter providing conclusive information about stability index of the inhibitor and frequently used for determination of inhibition efficiency. The lower $\Delta \mathrm{E}$ value indicates higher interaction between inhibitor and metal, better inhibition performance of the molecule due to the excitation energy to remove an electron from the last occupied orbital will be low $[48,50,63]$. Authors are not fully in agreement about the impact of dipole moment $(\mu)$ on corrosion inhibition. Some of the authors claim that high value of dipole moment is related to dipole-dipole interaction of metal and inhibitor hence leads to increase of inhibition efficiency $[42,53,64,65]$. In contrast, some of the authors have declared that increase of dipole moment leads to decrease in corrosion inhibition performance due to accumulation of the inhibitor molecules on the metal surface $[18,53]$. Quantum chemical parameters shown in Fig. 8 demonstrate that $\mathrm{I} 2$ has higher $\mathrm{E}_{\mathrm{HOMO}}$ for thiol forms, lower $\Delta \mathrm{E}$ values as compared to I1. Comparison of $\Delta \mathrm{E}$ reveals that $\mathrm{I} 2$ has better adsorption capability than I1 and inhibition efficiencies of the compounds follow the I2>I1 order, in accordance with the electrochemical test results.-

Since the inhibitor molecules act by adsorption, their attachment to the metal surface can be explained simply by the donor-acceptor approach. Physical adsorption is the first step of chemical adsorption and heteroatoms such as N, S, double bonds or aromatic rings play role in the adhesion of molecules to metal surface. Following physical adsorption, chemical adsorption can occur by electron transfer between the molecular orbitals of adsorbed molecule and metal. The Mulliken charges of the atoms in the investigated compounds were listed in Table 4 and numeration of atoms in molecular structures was shown in Fig. 1. Table 4 shows that, charges of 1, 3 and 9 numbered nitrogen atoms are higher than the other atoms of the compounds; in this way these atoms behave as negative charge centres of the investigated inhibitors and take place in physical adsorption on the positively charged $[66,67]$ steel surface. On the other hand, the $\mathrm{N}$ and $\mathrm{S}$ atoms cause an increase in the electron density of imidazole ring via their nonbonding electrons; in that case stronger adhesions onto the metal surface can occur. Therefore, these atoms contribute together to the inhibition performance. Afterwards, chemical adsorption may occur by sharing of electrons between molecular orbitals of metal and inhibitor.

\section{Conclusions}

- Two different drug precursor mercaptoimidazole derivative compounds were synthesized and assessed as possible corrosion inhibitors for 1020 type low 
carbon steel in $0.5 \mathrm{M} \mathrm{HCl}$ solution.

- EIS measurements demonstrated that impedance response increases by mercaptoimidazole concentration confirming adsorption of these molecules over the steel surface and these compounds act as corrosion inhibitor for low carbon steel in $0.5 \mathrm{M} \mathrm{HCl}$ solution.

- Potentiodynamic polarization curves showed that the synthesized mercaptoimidazoles behave as mixed type inhibitors.

- Adsorption of I1 and I2 inhibitors is spontaneous and obeys the Langmuir type adsorption isotherm; values of standard Gibbs free energy reveal that adsorption process includes both physisorption and chemisorption together.

- The ATR-FTIR and SEM analyses confirm presence of protective adsorbed layer on the metal surface after treatment of the steel electrode with mercaptoimidazoles in $\mathrm{HCl}$ solution.

- Quantum chemical calculations proved that $\mathrm{N}$ atoms of imidazole ring are likely to facilitate the adsorption of compounds on the steel surface and experimental results were supported by calculated $\mathrm{E}_{\mathrm{HOMO}}, \mathrm{E}_{\mathrm{LUMO}}$ and $\Delta \mathrm{E}$ quantum chemical parameters.

- Chlorine substituted mercaptoimidazole derivative $\mathrm{I} 2$ has better inhibition performance than its unsubstituted analogue I1.

\section{Acknowledgement}

The authors are grateful to Eskişehir Osmangazi University (ESOGU) for financial support. This work was supported by the Commission of Scientific Research Projects of ESOGU (Grant Number: 201819068).

\section{References}

[1] J. Ma, N.A. Choudhury, Y. Sahai, Renew. Sust. Energ. Rev., 2010, 14(1), 183-199.

[2] K.M. Usher, A.H. Kaksonen, I. Cole, D. Marney, Int. Biodeter. Biodegr., 2014, 93, 84-106.

[3] X.H. Li, S.D. Deng, H. Fu, T.H. Li, Electrochim. Acta, 2009, 54(16), 4089-4098.

[4] M.A. Hegazy, A.Y. El-Etre, M. El-Shafaie, K.M. Berry, J. Mol. Liq., 2016, 214, 347-356.

[5] J.H. Al-Fahemi, M. Abdallah, E.A.M. Gad, B.A.A.L. Jahdaly, J. Mol. Liq., 2016, 222, 1157-1163.

[6] P.E. Alvarez, M.V. Fiori-Bimbi, A. Neske, S.A. Brandan, C.A. Gervasi, J. Ind. Eng. Chem., 2018, 58, 92-99.
[7] Z.Y. Hu, Y.B. Meng, X.M. Ma, H.L. Zhu, J. Li, C. Li, D.L. Cao, Corros. Sci., 2016, 112, 563-575.

[8] D. Daoud, T. Douadi, H. Hamani, S. Chafaa, M. AlNoaimi, Corros. Sci., 2015, 94, 21-37.

[9] E. Gutierrez, J.A. Rodriguez, J. Cruz-Borbolla, J.G. Alvarado-Rodriguez, P. Thangarasu, Corros. Sci., 2016, 108, 23-35.

[10] I.B. Obot, N.K. Ankah, A.A. Sorour, Z.M. Gasem, K. Haruna, Sustain. Mater. Techno., 2017, 14, 1-10.

[11] X.M. Wang, H.Y. Yang, F.H. Wang, Corros. Sci., 2011, 53(1), 113-121.

[12] S.E. Kaskah, M. Pfeiffer, H. Klock, H. Bergen, G. Ehrenhaft, P. Ferreira, J. Gollnick, C.B. Fischer, Surf. Interfaces, 2017, 9, 70-78.

[13] R.W. Revie, H.H. Uhlig, Corrosion and Corrosion Control: An Introduction to Corrosion Science and Engineering, fourth ed., Wiley, 2006.

[14] I.B. Obot, S.A. Umoren, Z.M. Gasem, R. Suleiman, B. El Ali, J. Ind. Eng. Chem., 2015, 21, 1328-1339.

[15] I.B. Obot, N.O. Obi-Egbedi, Mater. Chem. Phys., 2010, 122(2-3), 325-328.

[16] I.B. Obot, N.O. Obi-Egbedi, S.A. Umoren, Corros. Sci., 2009, 51(8), 1868-1875.

[17] I.B. Obot, N.O. Obi-Egbedi, Corros. Sci., 2010, 52(1), 198-204.

[18] M.M. Kabanda, L.C. Murulana, M. Ozcan, F. Karadag, I. Dehri, I.B. Obot, E.E. Ebenso, Int. J. Electrochem. Soc., 2012, 7(6), 5035-5056.

[19] I.B. Obot, N.O. Obi-Egbedi, Curr. Appl. Phys., 2011, 11(3), 382-392.

[20] T.K. Chaitra, K.N.S. Mohana, H.C. Tandon, J. Mol. Liq., 2015, 211, 1026-1038.

[21] K. Hu, J. Zhuang, J.T. Ding, Z. Ma, F. Wang, X.G. Zeng, Corros. Sci., 2017, 125, 68-76.

[22] D.S. Chauhan, K.R. Ansari, A.A. Sorour, M.A. Quraishi, H. Lgaz, R. Salghi, Int. J. Biol. Macromol., 2018, 107, 1747-1757.

[23] P. Dohare, D.S. Chauhan, A.A. Sorour, M.A. Quraishi, Mater. Discov., 2017, 9, 30-41.

[24] R. Solmaz, G. Kardas, B. Yazici, M. Erbil, Colloid Surface A, 2008, 312(1), 7-17.

[25] A.A. Al-Sarawya, A.S. Fouda, W.A.S. El-Dein, Desalination, 2008, 229(1-3), 279-293.

[26] A.S. Fouda, A.A. Al-Sarawy, E.E. El-Katori, Desalination, 2006, 201(1-3), 1-13.

[27] A.Y. Musa, A.A.H. Kadhum, A.B. Mohamad, M.S. Takriff, A.R. Daud, S.K. Kamarudin, Corros. Sci., 2010, 52(2), 526-533.

[28] F. Bentiss, M. Traisnel, M. Lagrenee, Corros. Sci., 2000, 42(1), 127-146.

[29] F. Bentiss, M. Lagrenee, M. Traisnel, J.C. Hornez, Corros. Sci., 1999, 41(4), 789-803.

[30] Z. Zhang, S.H. Chen, Y.H. Li, S.H. Li, L. Wang, Corros. Sci., 2009, 51(2), 291-300.

[31] H.O. Curkovic, E. Stupnisek-Lisac, H. Takenouti, Corros. Sci., 2010, 52(2), 398-405. 
[32] O. Benali, L. Larabi, Y. Harek, J. Saudi Chem. Soc, 2010, 14(2), 231-235.

[33] O. Benali, L. Larabi, M. Traisnel, L. Gengembre, Y. Harek, Appl. Surf. Sci., 2007, 253(14), 6130-6139.

[34] A. Ghanbari, M.M. Attar, M. Mahdavian, Mater. Chem. Phys., 2010, 124(2-3), 1205-1209.

[35] M. Duran, S. Demirayak, Med. Chem. Res., 2013, 22(9), 4110-4124.

[36] J. Aljourani, K. Raeissi, M.A. Golozar, Corros. Sci., 2009, 51(8), 1836-1843.

[37] F. Bentiss, M. Lebrini, M. Lagrenee, Corros. Sci., 2005, 47(12), 2915-2931.

[38] J.G. Schantl, I.M. Lagoja, Heterocycles, 1997, 45(4), 691-700.

[39] R. Solmaz, E. Altunbas, G. Kardas, Mater. Chem. Phys., 2011, 125(3), 796-801.

[40] A. Chetouani, A. Aouniti, B. Hammouti, N. Benchat, T. Benhadda, S. Kertit, Corros. Sci., 2003, 45(8), 16751684.

[41] M. Behpour, S.M. Ghoreishi, N. Soltani, M. SalavatiNiasari, Corros. Sci., 2009, 51(5), 1073-1082.

[42] L. Jiang, Y.J. Qiang, Z.L. Lei, J.N. Wang, Z.J. Qin, B. Xiang, J. Mol. Liq., 2018, 255, 53-63.

[43] R. Solmaz, Corros. Sci., 2010, 52(10), 3321-3330

[44] Y.M. Tang, F. Zhang, S.X. Hu, Z.Y. Cao, Z.L. Wu, W.H. Jing, Corros. Sci., 2013, 74, 271-282.

[45] S.S.A. El Rehim, H.H. Hassan, M.A. Amin, Mater. Chem. Phys., 2002, 78, 337-348.

[46] Q.B. Zhang, Y.X. Hua, Mater. Chem. Phys., 2010, 119(1-2), 57-64.

[47] K.F. Khaled, Corros. Sci., 2010, 52(9), 2905-2916.

[48] R. Kumar, S. Chahal, S. Kumar, S. Lata, H. Lgaz, R. Salghi, S. Jodeh, J. Mol. Liq., 2017, 243, 439-450.

[49] C. Verma, E.E. Ebenso, I. Bahadur, I.B. Obot, M.A. Quraishi, J. Mol. Liq., 2015, 212, 209-218.
[50] S. Safak, B. Duran, A. Yurt, G. Turkoglu, Corros. Sci., 2012, 54, 251-259.

[51] K.F. Khaled, Mater. Chem. Phys., 2008, 112(1), 290300.

[52] M. Behpour, S.M. Ghoreishi, N. Mohammadi, N. Soltani, M. Salavati-Niasari, Corros. Sci., 2010, 52(12), 4046-4057.

[53] N. Yilmaz, A. Fitoz, U. Ergun, K.C. Emregul, Corros. Sci., 2016, 111, 110-120.

[54] C. Lai, B. Xie, L.K. Zou, X.W. Zheng, X. Ma, S.S. Zhu, Results Phys, 2017, 7, 3434-3443.

[55] V.R. Saliyan, A.V. Adhikari, Corros. Sci., 2008, 50(1), 55-61.

[56] A.M. Fekry, R.R. Mohamed, Electrochim. Acta, 2010, 55(6), 1933-1939.

[57] M. Shabani-Nooshabadi, M.S. Ghandchi, J. Ind. Eng. Chem., 2015, 31, 231-237.

[58] E.K. Ardakani, E. Kowsari, A. Ehsani, Colloid Surface A, 2020, 586. 124195.

[59] I. Ahamad, R. Prasad, M.A. Quraishi, Mater. Chem. Phys., 2010, 124(2-3), 1155-1165.

[60] V. Saraswat, M. Yadav, J. Mol. Liq., 2020, 297, 1-14.

[61] T. Zhou, J. Yuan, Z.Q. Zhang, X. Xin, G.Y. Xu, Colloid Surface A, 2019, 575, 57-65.

[62] M.A. Hegazy, A.M. Hasan, M.M. Emara, M.F. Bakr, A.H. Youssef, Corros. Sci., 2012, 65, 67-76.

[63] R. Kumar, R. Chopra, G. Singh, J. Mol. Liq., 2017, 241, 9-19.

[64] N. Khalil, Electrochim. Acta, 2003, 48(18), 2635-2640.

[65] M. Mahdavian, S. Ashhari, Electrochim. Acta, 2010, 55(5), 1720-1724.

[66] K.S. Jacob, G. Parameswaran, Corros. Sci., 2010, 52, 224-228.

[67] S. Deng, X. Li, X. Xie, Corros. Sci., 2014, 80, 276-289. 